\title{
Research and Application of In-situ Measure Device on High-Efficiency Convergence Deformation for the Large Cross Section Roadway
}

\author{
Chunde $\mathrm{Ma}^{1,2}$, Wei Fu${ }^{2}$, Sunxi $\mathrm{Hu}^{2}$, Yesun $\mathrm{Wang}^{2}$ and Yanan Zhou ${ }^{2}$ \\ ${ }^{1}$ Advanced Research Center, Central South University, Changsha, China \\ ${ }^{2}$ School of Resources and Safety Engineering, Central South University, Changsha, China
}

\begin{abstract}
In consideration of the disadvantages of the traditional contact-type measure methods for deformation measurement in large section roadway, the in-situ measure method and tool is developed with the theory of laser-based distance measuring. The novel multi degree of bracket set makes a stable connection between the primary measure points and portable laser rangefinder, which makes sure that the new device's position still kept in the same initial state after measure. Therefore, the accuracy and reliability of deformation measurement have been improved a lot so that having realized in-situ measurement. Then, a set of measure method have been created based on the new device and the improved cross arrangement method for measure points, which have been used in the long-term deformation monitoring task in large cross section roadway in Maluping mine area, and its noted data has revealed the deformation mechanism and ground pressure manifestation law in the deep roadways of soft rock under high-stress state, which providing the primary information as theoretical foundation for support design.
\end{abstract}

Keywords-large cross section roadway; surface convergence; portable laser range finder; multi degree of bracket set; in-situ measurement

\section{INTRODUCTION}

In the process of roadway (tunnel) construction, the initial stress state of surrounding rock changes after excavation, resulting in stress redistribution, then inducing the deformation of surrounding rock. The deformation obviously reflects structure stability condition of roadway's surrounding rock and support system. The features of the deformation manifestation provide an important reference to determine the reasonable support system and support time ${ }^{[1,2]}$. For underground rock engineering in shallow part, such as underground subway, water power station and nuclear waste repository, especially the large cross section roadway, the deformation measurement is one of necessary items in project standardized requirements because of its large span ratio and poor safety capacity. Therefore, in the engineering applications, it must be carried on the long-term monitoring of roadway deformation for guaranteeing safety ${ }^{[3]}$. For underground mining in deep part, roadway's deformation monitoring is also a required means to reveal the deformation failure mechanism and ground pressure manifestation law, as well as the prerequisite of its reasonable support design and safety production ${ }^{[4]}$.
Traditional deformation monitoring means generally is based on physical-contact methods, which is mainly suitable for the small cross section roadway. However, when it applied in large cross section roadway, it showed some obvious limitations ${ }^{[5,6]}$, such as poor accuracy, high labor intensity and affecting the regular production. In the past twenty or thirty years ,in some western countries, researchers have come up with some new methods of non-contact observation ${ }^{[7]}$, such as the three-dimensional analytical measurement with several sets of electronic theodolite ${ }^{[8]}$, the three-dimensional deformation measurement based on total station ${ }^{[9,10]}$, the close shot deformation measurement with close shot camera. etc $[11,12]$. These methods can be used to the deformation measure in roadway, but these devices also have some disadvantages, such as too expensive, complicated to operate and too heavy to carry. So these are not being widely promoted ${ }^{[13,14]}$.

The portable laser distance instrument is a cost-effective distance measure tool, which has been created in the past ten years. And it has certain advantages, such as high accuracy, surveying fast and being portable, which have been rapidly applied in monitoring, mine and other fields ${ }^{[15,16]}$. In recent years, some engineers in mining field have trying to directly apply it to deformation monitoring work ${ }^{[17]}$. However, after being used in practice, it has been found that it is unable to meet the requirement of absolute in-situ measurement, because there is no reliable fixed pattern except for manual holding, in spite of its feature of high precision (millimeter level). In other words, multi measure has to be in the same position like last time. Multiple measure or different people's operation may produce a certain manner deviation (reach some millimeters). The deviation for the regular distance measure may be small, but it is too large for a day to a few millimeters about rock roadway deformation, resulting in being unable to guarantee the results' reliability. In this paper, researcher have introduced a multi degrees of bracket set greatly improving precision and efficiency in measure process, which is used to make a solid connection between portable laser range finder and the measure point for meeting the requirements of the in-situ measurement.

\section{A NEW LASER IN-SITU MEASUREMENT DEVICE}

\section{A. Components of the Device}

The new device based on laser ranging measure device has been developed to accommodate the requirement of in-situ 
measure for large cross section roadways. The design idea is about a set of stable connection structure located on the middle of primary measure points and portable laser rangefinder. The connection structure can eliminate the effects of personnel operating and spatio-temporal variation of roadway in different frequency and sampling time by remaining the same initial state.

The new device consists of laser emission signal transmit-receive unit and the signal reflection unit. As shown in Figure II.

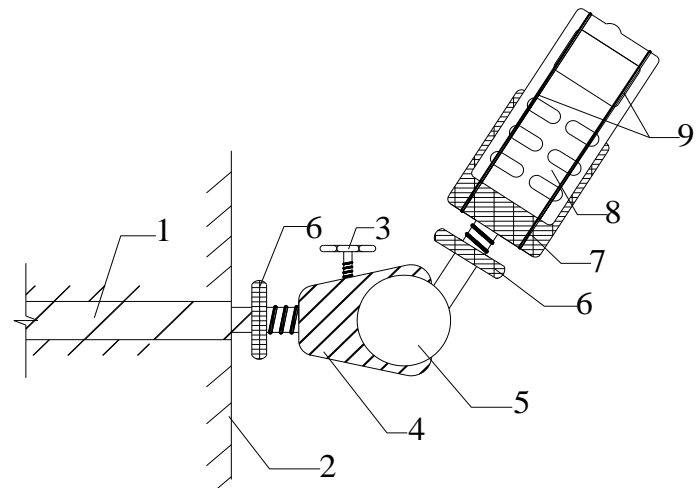

1-external thread short anchor 2-surrounding rock 3-universal ball knob 4-tripod head 5-tripod head screw 6-quick release plate 7-brackets with laser range finder 8-portable laser range finder 9-rubber belt

FIGURE I. THE STRUCTURE GRAPH OF LASER EMISSION SIGNAL TRANSMIT-RECEIVE UNIT

\section{B. Assemble Principle}

For arch-type subway, the primary-measure points regularly is located on the roof, spandrel, sides and floor. Specifically the sides and floor are chosen as the primary-measure points for its easy of handing. A short anchor with external thread installed tightly at every primary-measure points in surrounding rock mass. The portable laser range finder is fixed in brackets by two rubber belts. Tripod head's universal ball screw is screwed in brackets at the bottom of the threaded hole, screwed to the bottom of the hole and fixed with quick release plate by reversely screwing fixation.

Then, as an major part, tripod head base's threaded hole is screwed to the external thread of short anchor on primary measure point, spinning to the bottom of the hole and fixed with quick release plate by reversely screw fixation. Finally these parts formed a multi degree of testing construction, which makes the laser range finder freely rotate around the center point of universal ball.

After its visible light accurately pointing at common measure point, universal ball knob is fixed in this location. Therefore, the special structure have realized the in-situ measure of two measure points' distance, because every testing operation can be in the same initial state. The physical diagram of laser emission signal transmit-receive unit is shown in Figure II.
The device for reflecting laser signal is installed on the roof's common measure points, which is designed to be a short anchor welding with small ball and can be disposable installed for realizing the test results consistent in spite of the signal coming from different direction.

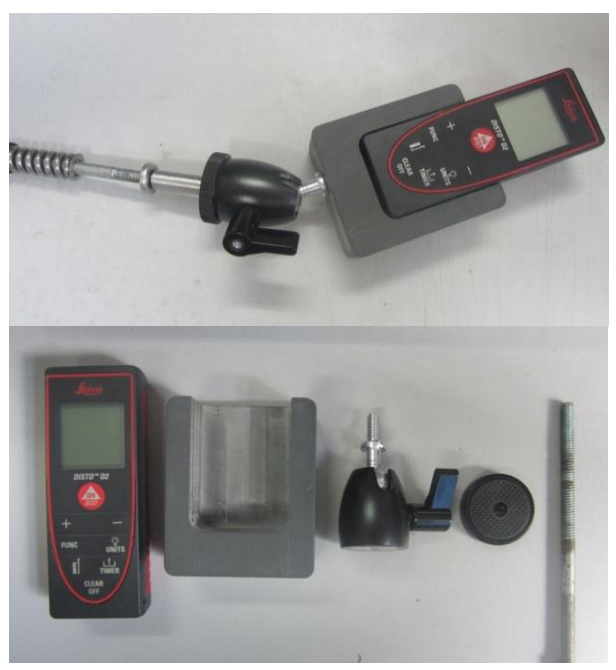

FIGURE II. THE PHYSICAL DIAGRAM OF LASER EMISSION SIGNAL TRANSMIT-RECEIVE UNIT

\section{Features of the Device}

To meet the requirements of actual measurement, the device has the following features.

(1) As the primary part of this device, the multi degree of bracket set is connected the primary measure points and portable laser range finder as medium material.

(2) Laser rangefinder bracket is processed by precision lathe according to its size. The internal groove fixed well with portable laser range finder by rubber belt. The special material is light-weight and high-strength resin materials similar to laser rangefinder's external material for eliminating lack-of-fit phenomenon caused by heat bilges cold shrink effect.

(3) The novel tripod head can guarantee that the laser rangefinder freely rotate around the same basis points (i.e. the center of the universal ball) as surrounding rock's deformation changed.

(4) Contact-parts processed by high-strength anti-corrosive material are able to accommodate the hostile engineering environment, such as short anchor made from stainless steel, tripod head made from aluminum alloy.

\section{MEASURE METHOD}

\section{A. Arrangement of Measure Points}

In actual operation, the measure point's arrangement is recommended to use the improved cross layout, that is to say, five points is unevenly distributed on the chosen large section. The common measure point $A$ is located at the middle of roof; The primary measure point B、B' separately located at left and right side on the straight wall; The primary measure point $\mathrm{C}$ located at the middle of floor. The common measure point $\mathrm{E}$ is located at left side of straight wall bottom to keep the length 
of $30 \mathrm{~cm}$ from the floor for conveniently operation. As shown in Figure III.

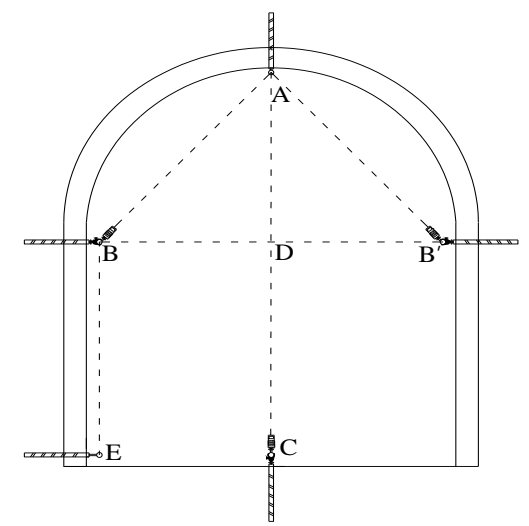

FIGURE III. THE LAYOUT OF MEASURE POINTS

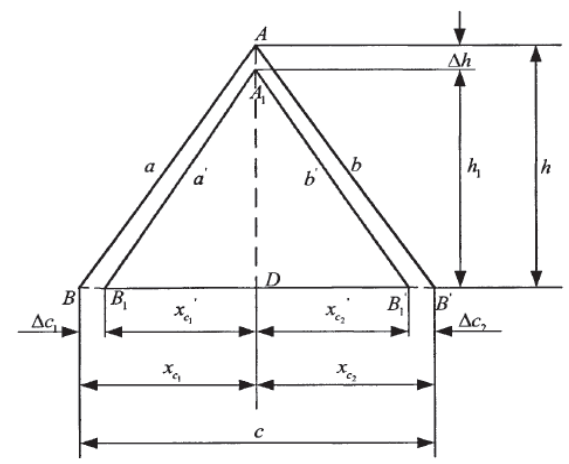

FIGURE IV.THE DIAGRAM OF CALCULATION PRINCIPLE

\section{B. Calculation Principle of Deformation}

As shown in Figure IV, according to the small deformation principle, the relative displacement of the sides, roof, floor and straight wall can be respectively measured through the obtained readings between $\mathrm{BB}^{\prime}, \mathrm{AC}$, and $\mathrm{BE}$. The deformation of the sides, roof, and floor can be obtained by the following methods.

Firstly, assuming that the closing triangle plane of $\mathrm{ABB}^{\prime}$ on each section perpendicular to the axis of the roadway. The displacement of BB' can be get by the BB' 's attachment.

Then mathematical deduce according to the Figure IV, assuming that:

$$
\begin{gathered}
A B=\mathrm{a}, A B^{\prime}=b, B B^{\prime}=c, B D=X_{c 1}, B^{\prime} D=X_{c 2}, A D=\mathrm{h} ; \\
A_{1} B_{1}=\mathrm{a}^{\prime}, A_{1} B_{1}^{\prime}=b^{\prime}, B_{1} B_{1}^{\prime}=c^{\prime}, B_{1} D_{1}=X_{c 1}^{\prime}, B_{1}^{\prime} D_{1}=X_{c 2}^{\prime}, A_{1} D_{1}=\mathrm{h} ; \\
s^{\prime}=1 / 2\left(a^{\prime}+b^{\prime}+c^{\prime}\right) ; s=1 / 2(a+b+c) \\
X_{c 1}=\frac{c^{2}+a^{2}-b^{2}}{2 c} ; X_{c 2}=\frac{c^{2}+b^{2}-a^{2}}{2 c} ; h=(2 / c) \cdot s(s-a) \cdot(s-b) \cdot(s-c) \\
X_{c 1}^{\prime}=\frac{c^{2}+a^{\prime 2}-b^{2}}{2 c^{\prime}} ; X_{c 2}^{\prime}=\frac{c^{2}+b^{\prime 2}-a^{2}}{2 c^{\prime}} ; h=\left(2 / c^{\prime}\right) \cdot s^{\prime}\left(s^{\prime}-a^{\prime}\right) \cdot\left(s^{\prime}-b^{\prime}\right) \cdot\left(s^{\prime}-c^{\prime}\right)
\end{gathered}
$$

Simultaneousing Eq. 1 and 2 can get the exact value of the deformation of sides, roof and floor.

$$
\begin{gathered}
\Delta c_{1}=X_{c 1}-X_{c 1}^{\prime} ; \Delta \mathrm{c}_{2}=x_{c 2}-X_{c 2}^{\prime} ; \Delta h=h-h^{\prime} \\
\Delta h^{\prime \prime}=\left(A C-A_{1} C_{1}\right)-\left(B E-B_{1} E_{1}\right)-\Delta h
\end{gathered}
$$

As shown in Eq. 3 and $4, \Delta c_{1}, \Delta c_{2}$ is roadway sides displacement; $\Delta h$ is roof subsidence; $\Delta h^{\prime \prime}$ is floor displacement.

\section{Measurement Procedure}

(1) Setting measure point. After excavation ,it has to set up the measure points according to improved cross layout, the point $\mathrm{B}, \mathrm{B}$ ' and $\mathrm{C}$ as the primary measure points tightly have been installed by short anchor with external thread. The measure point $\mathrm{A}$ and $\mathrm{E}$ is respectively located on the middle of the roof and the left side on roadway's bottom, which be set up a short anchor as signal reflectors.

(2) Laser in-situ measurement device's assemble and debugging. According to its structure, firstly the multi degree of bracket set must be assembled; the laser rangefinder is firmly fixed on the bracket set; then the multiple parts are tightly fixed on the primary measure point. Finally debugging the laser signal.

(3) Measurement. By the use of the new laser in-situ measurement device, based on $\mathrm{B}, \mathrm{B}$ and $\mathrm{C}$ as the primary measure points, the length of $\mathrm{AB}, \mathrm{BB}$ ', $\mathrm{AB}$ ', $\mathrm{BE}$ and $\mathrm{AC}$ can be accurately get. However, the noted value also can be affected by underground on-site environmental factors, resulting in certain system deviation. To weakening the influence of uncontrollable factors, personnel have to compute the average value based on multiple measurement readings.

(4) The roadway deformation calculation. According to the derived calculation formula at upper segment, the deformation law of roadway can be obtained over time for guiding production and support design.

\section{ENGINEERING APPLICATION}

\section{A. Engineering Background}

The Maluping mine area affiliated with Kaiyang phosphate mine in Guizhou province, its mining depth has reached $-600 \mathrm{~m} \sim-800 \mathrm{~m}$ pertaining to the deep mining. Due to its serious ground pressure appearance on red shale (soft rock) roadway's footwall, support work in main haulage roadway (large section three centered arch) is so hard. The early support method can not work so well that endangering safe mining and resulting in some phenomena such as regular roof caving, wall caving and floor heave. It is necessary to optimize the parameters about new support design based on the accurate ground pressure appearance rule. Therefore, one of the important task is long-term monitoring surface deformation in the new excavation roadway. The laser in-situ measurement device has been used in the project.

\section{B. Measurement in the Practical Field}

The measure position is located on the new excavation transportation roadway in $640 \mathrm{~m}$ middle of Maluping mine area. The arrangement of the measure points in the roadway's 
section has adopted of improved cross layout. The laser range finder's model is the Switzerland Leica D2 type used in measure, the precision $\pm 1 \mathrm{~mm}$.

Measure frequency arrangement. In the first month, after the excavation and supporting of roadway, measuring once a day. During the second month, measuring once in two days . After three months, measuring once a week until the displacement changed little. Finally stopping observation.

\section{Result Analysis}

According to the noted data, respectively mapping the surface deformation curve of two sides, roof and floor over time, as shown in Figure V and VI. In fact, The surface deformation curve can be simplified as piecewise linear type by the least squares method.

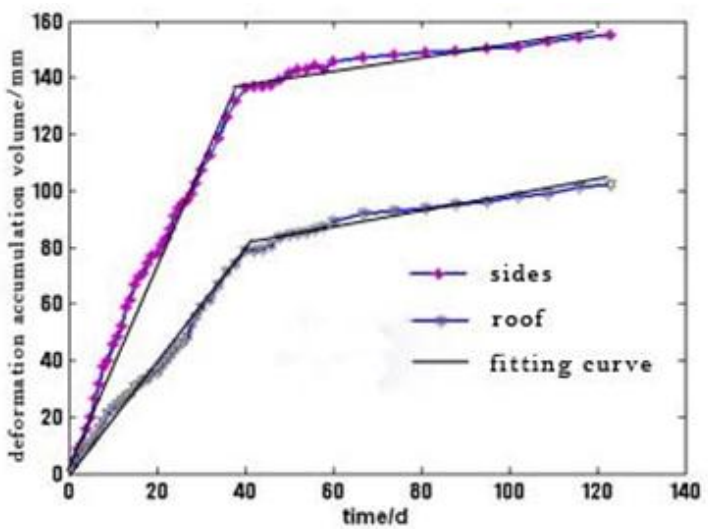

(a)

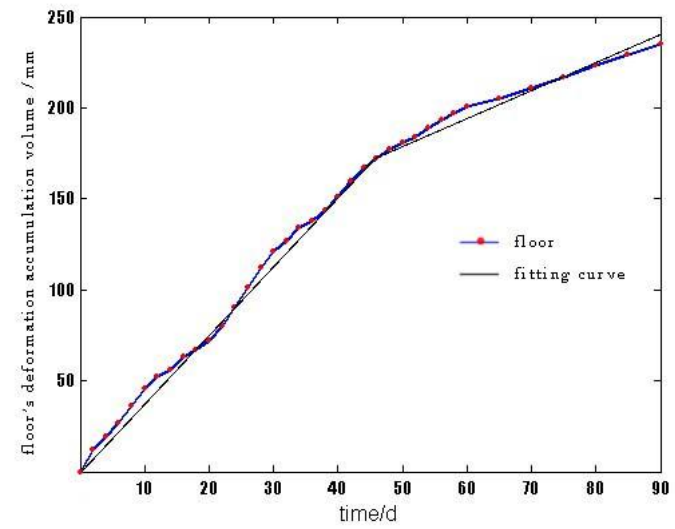

(b)

FIGURE V. THE SIDES, ROOF AND FLOOR 'S DEFORMATION ACCUMULATION VOLUME CURVE

(1) As shown in Figure V, the deformation accumulation volume of the sides, roof and floor have increased linearly, respectively reaching $155 \mathrm{~mm}, 105 \mathrm{~mm}$ after 120 days and $232 \mathrm{~mm}$ after 90 days. The accumulation volume and growth rate of floor's deformation are significantly larger than the roof and sides. After about 40 days, the overall deformation rate apparently slows down. The deformation process can respectively be summarized as the raising state and stable state, and there is a turning point of growth rate transformation in $\mathrm{T}=40$.
(2) As shown in Figure VI, 50 days ago, the growth rate of floor's deformation jumped in the saw-tooth pattern, the overall growth rate is within the range of $10 \sim 25 \mathrm{~mm} / \mathrm{d}$, then declining to $9 \mathrm{~mm} / \mathrm{d}$ in stable state.

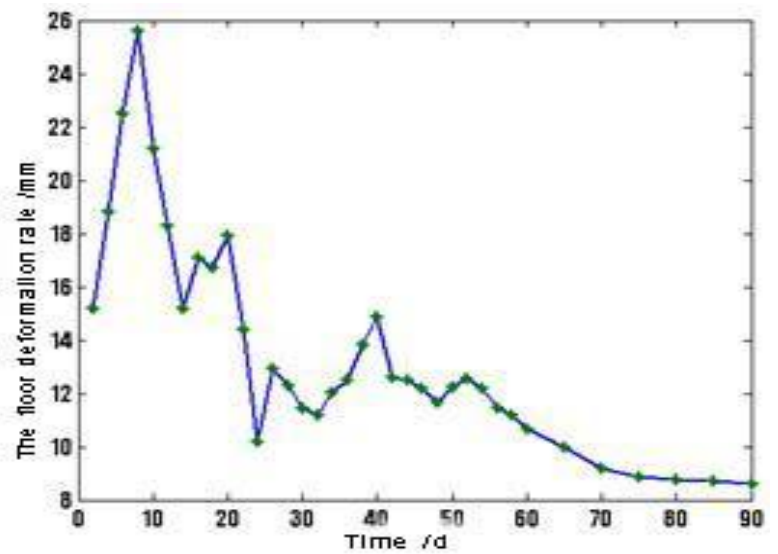

FIGURE VI. THE FLOOR'S DEFORMATION GROWTH RATE CURVE

\section{CONCLUSION}

(1) The multi-degree bracket set have solved the problem of in-situ measure. Based on those advantages of portable laser rangefinder, the novel laser in-situ measure device can be conveniently installed, high-precision, and unaffected by underground work environment, greatly improved the measure's efficiency.

(2) On the theory of small deformation principle and trigonometric function method, some deformation calculation formula of roadway surface has been derived by the measure points' arrangement form of the improved cross layout.

(3) The testing methods has been applied in the roadway deformation monitoring work of soft rock, at $640 \mathrm{~m}$ middle level in Kaiyang phosphate mine area. The accurate ground pressure appearance law have been concluded, which provide a reliable theory for its supporting design.

(4) The novel device and measure method consisting of a set of solutions is suitable for all kinds of large cross section roadway to measure convergence deformation. So it is worth to be popularized.

\section{REFERENCE}

[1] WANG Qi-sheng, LI Xi-bing, LI Di-yuan. Surrounding rock deformation properties and determination of support parameters of soft rock roadway in deep mine [J]. Journal of China Coal Society, 2008,No.16304:364-367. (in Chinese)

[2] Stolarczyk L G. Long range multiple point wireless control and monitoring system: US, US5087099[P]. 1992.

[3] CAO Ping, WANG Fei, QIU Guan-hao, LI Kai-hui, CAO Ri-hong. Support technology and its application for large deformation of soft rock roadway $[\mathrm{J}]$. Journal of Safety Science and Technology,2014,v.1008:69-74. (in Chinese)

[4] HE Man-chao, XIE He-ping, PENG Su-ping, JIANG Yao-dong. Study on rock mechanics in deep mining engineering $[\mathrm{J}]$. Chinese Journal of Rock Mechanics and Engineering ,2005,16:2803-2813. (in Chinese)

[5] FENG Zhong-ren, ZHANG Xing-cai, ZHANG Shi-xiong, LIAN Yue-quan. Montoring study on drift deformation of daye iron mine[J]. Chinese Journal of Rock Mechanics and Engineering, 2004,03:483-487. (in Chinese) 
[6] LIU Quan-sheng, SHI Kai, HUANG Xing. Analysis on site monitoring of roadway under disturbed effects by excavation of neighboring roadways [J]. Journal of China Coal Society,2011,06:897-902. (in Chinese)

[7] Q.Nadeem,S.J.Na. Deformation behavior of laser bending of circular sheet metal[J]. Chinese Optics Letters,2011,05:47-51.

[8] Saito K, Miyoshi T, Yoshikawa H. Noncontact 3-D Digitizing and Machining System for Free-Form Surfaces[J]. CIRP Annals Manufacturing Technology, 1991, 40(1):483-486.

[9] Chang C C, Xiao X H. Three-Dimensional Structural Translation and Rotation Measurement Using Monocular Videogrammetry[J]. Journal of Engineering Mechanics, 2009, 136(7):840-848.

[10] Zhang C S. Mine laneway 3D reconstruction based on photogrammetry[J]. Transactions of Nonferrous Metals Society of China, 2011, 21(S3):686-691.

[11] Se S Y S, Jasiobedzki P, Parry D O, et al. 3D imaging system: US, US 7860301 B2[P]. 2010.

[12] Y.I Abdel-Aziz, H.M. Karara, Michael Hauck. Direct Linear Transformation from Comparator Coordinates into Object Space Coordinates in Close-Range Photogrammetry *[J]. Photogrammetric Engineering and Remote Sensing, 2015, 81(2):103-107.

[13] Wang F, Zhen S, Wu S. A non-contact measurement based on a new proximity sensor[J]. Machinery Manufacturing Engineer, 2003.

[14] Barbeau E M, Krieger N, Soobader M J. Working class matters: socioeconomic disadvantage, race/ethnicity, gender, and smoking in NHIS 2000.[J]. American Journal of Public Health, 2004, 94(2):269-78.

[15] DUAN Lin-lin, CUI Yi-ping. Principle and Design of a New Type of Portable Laser Rangefinder [D].Chinese Journal of Electron Devices, 2009. (in Chinese)

[16] LI Jun-feng, RUAN Lin-lin, YAO Dan. Principle and Implementation of Portable Laser Range Finder [J].Geomatics\& Spatial Information Technology, 2014(1):103-105. (in Chinese)

[17] XIAO Guo-feng, YANG Jun-bo, CHEN Cong-xin, A new method of laser convergence monitoring and its precision assessment[J] Rock and Soil Mechanics, 2014,03:896-900. (in Chinese) 